des Boraxweinsteins, wo ein Zusatz von Weinsäure aus demselben Veinstein fällt, lälst sich, übereinstimmend mit den obzwar schwieriy unternommenen Analysen folgern, dals beim Zusammentreffen des Weinsteins mit dem Borax auf nassem Wege, erster zu einfach-weinsaurem Kali sich reducirt; der zweite Antheil Weinsäure ist auch in zureichender Menge vorhanden, um mit dem Natron des Borax einfach - weinsaures Natron zu bilden und die isolirte Borsäure zu sättigen. Diese Doppelsäure nun ist so fest gebunden, dafs sie vom Weingeiste nicht aufgelöst wird, sowie überhaupt der Boraxweinstein im Alkohol mnlöslich ist, beim Sättigen mit hohlensäuerlichem Ammoniak aber sich sehr leicht auflöst; vom Wasser gehen nur blols 3 Atome mit in die neue Verbindung und man murs ron 20 Gewichtstheilen Borax und $60 \mathrm{Gewich}$ tsth. Weinstein, zusammen 80, auch 70, oder $\frac{7}{8}$ Boraxweinstein erhalten.

Die Formel für dieses Präparat wäre daher ähnlich der von Duflos:

$$
\mathrm{Na} \overline{\mathbf{T}}+3 \dot{\mathrm{K}} \overline{\mathbf{T}}+\dddot{\mathrm{B}}_{2} \overline{\mathrm{T}}_{2}+3 \mathrm{Aq} \text {. }
$$

und der stöchiometrische Werth $=835,477(0=10)$, welcher auch dem nach der ersten Ansicht gefolgerten gleich ist; in $100 \mathrm{Gewichtstheilen} \mathrm{wären} \mathrm{daher} \mathrm{enthalten} \mathrm{:}$ $\dot{\mathrm{Na}} \overline{\mathrm{T}} 14,5+\dot{\mathrm{K}} \overline{\mathrm{T}} \mathbf{5 1 , 4}+\dddot{\mathrm{B}} 10,4+\overline{\mathrm{T}} 20+$ Aq. 3,7.

\title{
Chemische Bemerkungen;
} vom

Apotheker Demong in Sarstedt.

\section{Ueber Bittermandelwasser.}

Nach der vom Hrn. Dr. Ge i s el er in dieser Zeitschr. 2. R. Bd.X, 50. bekannt gemachten Methode zur Berei- 
tung der Aquae amygdalar. amarar. concentratae, welche darin besteht, die vom Oel durchs Auspressen befreiten bittern Mandeln zuvor mit Wasser und der nach der Pharmakopüe vorgeschriebenen Menge Weingeist bei 30 bis $40 \mathrm{Grad}$ Réaum. einige Stunden hindurch zu digeriren und darauf die Masse in das in der Blase vorher kochend gemachte Wasser zu schütten, worauf dann die Destillation bei märsigem Kohlenfeuer sofort langsam vorgenommen wird, habe ich stets ein sehr wirksames Bittermandelwasser vou vorschriftsmäfsigem Blausäuregehalt erhalten, welches ${ }_{2}$ in ganz damit angefuillten Gläsern aufbewahrt, sich lange Zeit unverändert crhält, ohne Flocken oder einen Bodensatz abzuscheiden, was immer der Fall war mit dem nach der Hannov. Pharm. bereiteten Bittermandelwasser.

Uebrigens bin ich der Meinung, dafs die von Wöhler und Liebig ertheilte Vorschrift zur Bereitung des Bittermandelwassers aus Amygdalin und Mandelnemulsion, vor allen übrigen Bereitungsmethoden den Vorzug und daher die Beachtung der Aerzte im hohen Grade verdient, zumal da die Darstellung des Amygdalins gar keine Schwierigkeiten hat, wenn man nur hinreichend starken Alkohol zum Exirahiren der vorher vom fetten Oel befreiten bittern Mandeln anwendet.

\section{Ueber Zinkoxyd.}

Das Verfahren vom Hrn. C. Fredek ind in Riga zur Bereitung eines reinen Zinkoxyds, welches darin besteht, der sauren Auflösung des schwefelsauren Zinkoxyds, nachdem aus derselben vermittelst Schwefelwasserstoff das Cadmium gefällt worden, chlorichtsaures Natron zuzusetzen, und die Mischung unter öfterm Um- 
rühren 24 Stunden stehen zu lassen, worauf durch vorsichtiges Zusetzen von kohlensaurem Natron das Eisenoxyd vollkornmen gefällt wird, welches man dann durch Absetzen und Filtriren trennt, habe ich ebenfalls sehr zweckmäfsig gefunden.

Ich habe auf diese Weise aus der seit längerer Zeit gesammelten Flüssigkeit aus der Döbereinerschen Zündmaschine, welche etwa 12 bis 15 Pfund schwefelsaures Zinkoxyd enthalten mochte, $4 \mathrm{Pfd}$. des reinsten völlig eisenfreien Zinkoxyds erhalten.

Die Methode, dunch Chlor das Eisen aus der schwefelsauren Zinkauflösung abzuscheiden, ist jedoch nicht neu, indem ich schon im Jahre 1818, während meiner Anwesenheit in Berlin, im Ilause meines verewigten Freundes und Lehrers, des Obermedicinalassessors S ch r ader, auf Veranlassung desselben, Chlorgas zu diesem Zwecke anwandte, was indessen nicht so zweckmäfsig, wie chlorichtsaures Natron der sauren Fï̈ssigkeit hinzugesetzt, sich bewährte.

\section{Prüfung auf Salpetersäure.}

Vor Kurzem habe ich Gelegenheit gehabt, von der zweckmärsigen Methode nach Angabe von Desbassins de Richemont, kleine Mengen von Salpetersäure und salpetersaurer Salze vermittelst Schwefelsäure und Eisenvitriolauflösung zu entdecken, welche vom Hrn. Hofrath $B$ randes und Hrn.W es sel wiederholt und bestätigt wurde, mich zu überzeugen. (S. diese Zeitschr. 2. R. Bd. $V, 51$.)

Es wurde mir nïmlich von Seiten des Amts Ruthe im Auftrage Königl. Landdrostei Hildesheim ein Pulver, welches von einer Quaclsalberin einer lranken Frau, die zwei Tage nach dem Gebrauche desselben starb, gereicht 
worden war, zur Untersuchung anf schädliche Stoffe zugestellt. Die damit vorgenommene chemische Prüfung liefs metallische Stoffe darin nicht entdecken; das Pulver bestand aus vegetabilischen Körpern, Alandswurzeln, Galgantwurzeln u. dergl. in Verbindung mit wenigem Salpeter, in welchem die Salpetersänre auf die obenerwähnte Art ganz unzweideutig nachgewiesen wurde.

Ich gelangte zu der Ueberzeugung, dafs das Pulver, insoweit die Reagentien auf schädliche Stotfe sich wirksam zeigen, eines schädlichen Inhalts hicht sei, und dafs daher dasselbe auf den gesunden menschlichen Organismus nicht heftig, vielweniger lebenşefährlich einzuwirken vermöge, ob aber dieses Pulver auf den kranken menschlichen Körper lebensgefährlich und in heftigen Krankheiten den Tod beschleunigen könne, darüber konnte ich ein Urtheil mir nicht anmaalsen, und mufste dieses lediglich der ärztlichen Entscheidung anheimstellen.

\section{Dritte Abtheilung.}

\section{Centralbericht.}

\section{Das Daguerrotyp.}

Die Einwirkung des Lichts auf verschiedene Substanzen ist der Gegenstand zahlreicher und langjähriger Versuche gewesen, welche $\mathrm{Ni}$ epce nnd $\mathrm{D}$ a g u e r re, Besitzer des Dioramas in Paris, wahrscheinlich in Folge der Requisite dieses Etablissements, unternahmen und die letztern zur Einrichtung eines Apparates führten, wodurch die Bilder der Camera obscura sich fixiren lassen, der den Namen des Daguerrotyp erhalten hat. Es ist aus allen öffentlichen Blätern bekannt, welches Aufsehen diese Entdeckung gemacht hat, und welche sanguinische 